\title{
Standards of Practice in Postsecondary Special Needs Programming: Student and Administrator Opinion
}

\section{J. REED, E. LUND-LUCAS \& K. O'ROURKE}

Ryerson University, Trent University, Loyalist College

\section{ABSTRACT}

Standards of practice for postsecondary special needs programmes are an important element to determining programme effectiveness and programme successes. A number of groups have now suggested practice standards for postsecondary special needs programmes. We amalgamated these suggested practices and queried Ontario students and administrators regarding their opinion of these practice standards. Overall, strong support for most suggested practices was found among students and administrators. However, administrators less strongly supported practices that required enhanced funding, staffing and resources. In addition, students less strongly supported practices that could reduce individualized programming and increase time commitments. Administrators pointed out barriers to achieving practice standards. Time commitments, workload, funding, unclear working definitions (i.e., standards for transition, disabilities) and institutional policy constraints were barriers to achieving suggested practice standards.

\footnotetext{
The authors would like to thank the students and programme administrators across Ontario for their participation in this project. The authors would also like to thank Ron Collis for his continued computer and analysis support. In addition, we would like to acknowledge Trent University and Loyalist College Special Needs Programmes for administrative and resource support.
} 


\section{RÉSUMÉ}

Les normes qui régissent les pratiques des programmes adaptés du niveau postsecondaire représentent un élément important dans la détermination de l'efficacité de ceux-ci et de leur succès. Un certain nombre de groupes ont suggéré des normes de pratique pour ces programmes éducatifs spéciaux. Nous avons regroupé ces pratiques suggérées et avons interrogé des étudiants en Ontario ainsi que des administrateurs afin d'obtenir leur opinion sur ces normes de pratique. En général, un soutien important à l'égard de la plupart des pratiques suggérées a été noté parmi les étudiants et les membres de l'administration. Toutefois, les administrateurs ont réservé un accueil moins enthousiaste aux pratiques qui nécessitent une augmentation du financement, du personnel et des ressources. De plus, les étudiants ont moins bien accueilli les pratiques qui seraient susceptibles de réduire les programmes personnalisés et qui augmenteraient leur investissement en terme de temps. Les administrateurs ont précisé les obstacles à la réalisation de ces pratiques; les barrières identifiées pour leur mise en place furent : l'investissement en terme de temps, la charge de travail, le financement, des conditions de travail mal définies (c'est-à-dire les normes de transition, d'incapacités) et les contraintes des politiques institutionnelles.

Service provision for students with disabilities has become increasingly important in today's climate. Canadian and American sources cite an increasing number of students with disabilities entering postsecondary institutions (e.g., Fichten, 1995; Greenbaum, Graham \& Scales, 1995; Hill, 1992; University of Alberta, 1993; Vogel, Leyser, Kwyland \& Brulle, 1999; Wilchesky, 1986) and students with learning disabilities make up the largest proportion of these students (Stewart, Cornish \& Somers, 1995; Vogel et al., 1999). Researchers have estimated that between thirty and fifty percent of students with learning disabilities, who enter postsecondary institutions, complete their education. These graduation rates do not differ from non-disabled students (Fichten, 1995; Greenbaum et al., 1995; Vogel et al., 1999). Studies also show that 
employment rates for students with learning disabilities who have attended postsecondary institutions are significantly higher than students with learning disabilities who do not attend (Greenbaum, Graham \& Scales, 1996) and are equivalent to non-disabled postsecondary graduates (Statistics Canada, 1997).

While there are increasing numbers of students with disabilities entering postsecondary institutions, these students represent only $0.25 \%$ of the Canadian population with disabilities (Leitch, 1998). This low proportion may be due to barriers that exist for entry into these institutions. Fichten (1995) argued that both systematic and individual barriers exist for students with disabilities at postsecondary institutions. Some of these barriers include attitudes of service providers and faculty, lack of funding for appropriate accommodations, discrimination, lack of knowledge of special needs programmes and student rights (Fichten, 1995; Greenbaum et al., 1996; The National Educational Association of Disabled Students [NEADS], 1999a, 1999b; Raskin, Goldberg, Higgins \& Herman, 1999). Some of these barriers to education for students with disabilities might be overcome with the development of standards of practice in postsecondary programming.

The Canadian Association of Disability Service Providers in Postsecondary Education (CADSPPE) (1999) and Hill (1992) have called for postsecondary institutions to develop policies and practices that ensure students in special needs programmes are dealt with equitably. Saucier and Gagliano (1998) explained that policy discrimination is evident in postsecondary institutional administrative practice and in education accessibility. One way to assess policy discrimination is through programme evaluation. Those involved in postsecondary special needs programming argue that programme evaluation is necessary to ensure that students are treated equitably (e.g., Collier, 1999; University of Alberta, 1993). However, Brinkeroff, Shaw and McGuire (1993) found that many postsecondary institutions are not collecting data to show programme effectiveness. One reason why programme evaluations are not conducted may be the lack of accepted standards of practice.

The development of standards for postsecondary special needs programmes has become a focus of a number of groups (e.g., Association of 
Higher Education and Disability [AHEAD], 1996; CADSPPE, 1999; Chapman University, 1999; NEADS, 1999a; University of Alberta, 1993) and individual researchers (see, for example, Albert \& Fairweather, 1990; Rose, 1991). Theoretically, standards of practice would provide a number of benefits to special needs programmes including, consistency of practice across institutions, minimal standards for acceptable practice, quality assurance, and a baseline for performance evaluation. While many regulated professions have adopted educational and practice standards (see, for example, Rogers, 2000), most post-secondary programmes do not follow standards developed outside of their individual institutions unless they are seeking accreditation from a professional association or regulatory body. One reason that inter-institutional standards for post-secondary education may not have been developed or followed in many programmes might be the lack of research into the effect of standards on educational programming. However, a few organizations have reported direct benefits resulting from instituting practice standards. Benefits included increased entry-level competencies, and guidelines for curriculum development and public/professional education (Rogers, 2000; Royal College of Radiologists Working Group, 1992).

Although CADSPPE (1999) has made recommendations to closely examine programme standards developed by AHEAD (1996), and NEADS (1999a) has made recommendations as to best practices in special needs programmes, studies of attitudes of service providers and students to these standards have not yet been conducted. The acknowledgment of standards by both service providers and clients represents a first step in developing guidelines for special needs programmes. We amalgamated suggestions for practice standards in postsecondary disability/special needs programmes and designed a survey to solicit the opinions of programme administrators and students across Ontario regarding these practices. While the analysis below shows that suggested standards of practice are broadly accepted in Ontario postsecondary institutions, the analysis also outlines significant differences between student opinion and the opinion of programme administrators. In addition, the analysis outlines shortfalls in some standards that make them difficult to implement. 


\section{METHOD}

\section{Participants}

Postsecondary Administrators. Administrators in all Ontario postsecondary institutions, where special needs services were advertised through institutional web sites or the Ontario Ministry of Education and Training web site, were asked to participate in the practice standards survey. In total 40 postsecondary institutions advertised services ( 16 universities, 24 colleges). An attempt was made to contact each institution first by e-mail, then by fax. If no response was received a telephone call was made to the institution to find out if they had received our communications and if they intended to participate in the survey. At eight institutions e-mail and fax methods failed. These institutions were telephoned but the calls were either not connected or no method of leaving messages was available. Thus, it was confirmed that 32 postsecondary institutions received the survey and 24 administrators from 21 institutions ( 8 universities, 13 colleges) responded to the survey. This represents a $66 \%$ response rate from contacted institutions. In addition, the proportion of university to college responses was reflective of the distribution of programmes in Ontario. Of those responding schools, seven $(22 \%)$ were large institutions $(>10,000$ fulltime undergraduates).

Student Participants. Packets of student surveys were sent to all 21 institutions that participated in the administrator portion of the survey. Administrators were asked to distribute at least eight surveys to students in their programme (this number was limited due to time constraints on the part of the administrators). To protect confidentiality of both the students and programmes, each institution received an identifiable return envelope so that study investigators would know how many institutions participated but the envelope or surveys did not identify which institution returned surveys. In all 12 institutions participated in the survey process and 104 surveys were distributed. Sixty-two surveys were returned completed representing $60 \%$ of those distributed. 


\section{Design and Procedure}

The content of the student and administrator best practices surveys were developed through review of many sources including a general literature review and specific practice suggestions made by:

- Programme Self Evaluation Project: Discussion Paper, Reed (2000)

- Success Indicators: Virtual Centre of Excellence (2000)

- The Association of Higher Education and Disability (1996)

- The Canadian Association of Disability Service Providers in Postsecondary Education (1999)

- The National Education Association of Disabled Students (1999 a \& b)

- University of Alberta (1993)

The content of the administrator survey focused on nine areas including best practice in programme administration, admissions, assessment, human resources, programme development, transition and outreach, advising and counseling, professional development, and advocacy. Within each content area specific practices (as suggested by the sources listed above) were stated. Specific practices in each content area included advising, communication, advocacy, quality assurance, and accessibility of resources. For a list of specific practices by area see Tables $1,2,3,6,8,9,10,11$, and 12 . To ensure that survey questions and suggested practices were understood, all developed survey questions were pre-tested on two programme administrators who were asked to suggest changes in wording and indicate their understanding of the questions. Any questions that were difficult to understand or needed wording changes were once again sent to both administrators.

The administrator survey was designed as both an e-mail back and fax back survey. The e-mail version was written in HTML code and emailed directly to participant programmes. The survey was designed such that it could be filled out online. The responses to each e-mail back survey were collected in a secure and protected database. Each survey was coded such that more than one survey being returned from the same 
participant would be flagged (this never happened). The fax version was identical to the e-mail back version except that it functioned as a fivepage paper and pencil survey that was faxed back to a toll free number.

Once pre-testing was complete, the administrator participant sample was asked to rate their level of agreement with each practice using a five point behaviourally anchored Likert scale $(1=$ strongly disagree, $5=$ strongly agree). Administrators also indicated how frequently (never, rarely, usually, always) their programme follows each practice. When administrators noted that they disagreed with or did not follow a practice (rarely, never) they were asked to explain why.

The student survey was designed as a four-page paper and pencil survey. The content of the student survey was identical to that of the administrator survey, except that areas where students would have limited knowledge were removed (i.e., human resources, professional development) and students were only asked to rate their level of agreement with each practice on the five point behaviourally anchored Likert scale ( $1=$ strongly disagree, $5=$ strongly agree). When students disagreed with a practice they were asked to explain why. To ensure that survey questions and suggested practices were understood, all developed survey questions were pre-tested on 35 students in special needs programmes, who suggested changes in wording and indicated their understanding of the questions asked. These pilot students indicated that they understood all questions but some students needed clarification on task instructions. Based on these comments instructions were modified.

Once pre-testing was complete, programme administrators were asked to randomly distribute surveys to students. Each programme was asked to distribute a minimum of eight surveys. Programme administrators indicated to us that they had little time to distribute and collect surveys, thus a minimum of eight was chosen because administrators agreed that this number would not constitute a large increase in workload. Paper and pencil surveys were returned to the programme in a sealed envelope. The surveys once collected by the programme were forwarded to the first author via mail. An on-line version of the survey was also made available to programmes that wished to have the students complete the survey online (two programmes chose this option). For these programmes the 
e-mail addresses of students that consented to participate were used to directly contact each student and send each student a survey. The on-line version of the survey was identical to the paper and pencil version. The on-line responses were returned to a secured and protected database and responses were coded such that more than one survey being returned from the same participant would be flagged (this never happened).

\section{Data analysis}

The qualitative data were analyzed from five perspectives. First, the overall agreement with suggested practices was assessed for administrator and student groups. This was accomplished by frequency/proportion counts of those who at least somewhat agree with a practice (rating 4 or 5) on the Likert scale. Second any practice that had less than $75 \%$ agreement was flagged. We considered any practice where agreement reached $75 \%$ or more as well accepted. A content analysis (by theme) was performed on comments made by those who disagreed with the flagged practices to ascertain reasons for lower acceptance. Third, overall participation of administrators/programmes with each practice was assessed via proportion and a content analysis (by theme) was performed on comments made by administrators to practices that received less than $75 \%$ participation. Note that proportions of overall administrators following each practice (since three programmes had two administrator participants) did not differ significantly from the proportions of programmes following each practice, thus overall administrator participation is presented in the result section. Fourth, administrators were asked to indicate minimum programme needs and minimum assessment criteria. Here, the proportion of administrators choosing each item/tool is reported. Fifth, for practices that were not well supported by either administrators or students, two analyses were conducted to show any significant differences in opinion. First, a confidence (.95) analysis about proportions was completed to determine significant differences between the proportion of administrators and the proportion of students supporting a practice. Second, a t-test was conducted to determine differences in ratings made by administrators and students. In addition, we examined possible differences in opinion between colleges and universities and between large 
and small institutions. Here, we flagged questions where differences in agreement exceeded $30 \%$. Thirty percent was used because in our lowest $\mathrm{N}$ category a minimum of 3 programmes would represent a proportion of greater than $30 \%$. However, due to small sample size for differences between large and small institutions and between colleges and universities, the information provided is only descriptive.

\section{SUMMARY OF FINDINGS}

\section{Administrative Practices}

Administrators were asked to assess thirteen possible best practices relating to programme administration (see Table 1). Administrators first indicated if they agreed with the practice, and second administrators indicated the frequency with which their programme follows each practice. Students also assessed their level of agreement with five of these practices.

As illustrated in Table 1, strong agreement was found among administrators and students with all administrative practices; except that only $59 \%$ of administrators supported budgets being reviewed by an independent assessor. Comments suggested that administrators were concerned about who this independent assessor might be. While students supported administrative practices, some students commented that they often do not feel comfortable asking for administrative information.

Three practices were not consistently followed by administrators (see Table 1). These practices included independent assessment of the budget (59\% follow), participation in research activities ( $29 \%$ follow), and informing faculty and staff of programme goals (74\% follow). Administrators felt an independent assessor likely would not understand the needs of the programme. In addition, administrators in large institutions less often agreed with and followed budgets being reviewed by an independent assessor and colleges less often followed this practice. Some administrators also noted that one barrier to providing information to faculty or staff is the low attendance from these groups at workshops and training sessions. 
Table 1

Percent Agreeing With and Following Suggested Administrative Practices

\section{Practice}

\section{$\%$ Agree $\%$ Agree $\%$}

Administrators Students Follow

1. Special needs staff know and communicate emergency procedures to students.

2. The programme has formal processes to deal 86

$75 \quad 79$
with student complaints and grievances.

3. The programme interprets and communicates 92

NA

87
legal and legislative mandates.

4. The Special Needs Administrator advocates 96

NA

78
for programme funds.

5. The special needs budget is annually 59

NA 59
reviewed by an independent assessor.

6. The special needs programme administrator 86 NA 87 develops and administers a budget.

7. The special needs programme participates 75 NA 29 in research activities (i.e., research projects).

8. There is open communication between the 100 NA $\quad 87$ special needs programme and government, community organizations and the institution.

9. The programme maintains up-to-date data 96 $77 \quad 83$ banks on community services, funding, legislation and institutional services.

10. Students, faculty and staff are made aware 96 $89 \quad 74$ of programme goals.

11. Programme administrators and staff develop 100 NA 83 and assess programme goals.

12. Policies and procedures are reviewed and evaluated annually.

13. Special needs programmes have documented 100 92 NA 83 policies and procedures. 
Table 2

Percent Agreeing With and Following Suggested Admissions Practices

Practice

Practice
$\%$ Agree $\%$ Agree $\%$

Administrators Students Follow

1. Referral to special needs can come from many $\quad 100 \quad 000$ sources (self, family, high school, faculty).

2. Postsecondary recruitment and admissions staff are knowledgeable of special needs $i$ ssues and admission procedures.

\begin{tabular}{lllll}
\hline 3. Special Needs Staff participate in recruitment & 75 & NA & 54 \\
activities on and off campus. & & & \\
\hline $\begin{array}{l}\text { 4. Students with special needs are actively } \\
\text { recruited to the postsecondary institution. }\end{array}$ & 67 & 46 & 52 \\
\hline $\begin{array}{l}\text { 5. Specialized admission procedures are in } \\
\text { place for and advertised to students with } \\
\text { special needs. }\end{array}$ & 67 & 75 & 58 \\
\hline
\end{tabular}

\section{Admission Practices}

Administrators were asked to assess five possible best practices relating to admissions. Students assessed four of these practices. The five practices are found in Table 2 .

As illustrated in Table 2, strong agreement was found among administrators and students to the use of two admission practices, and less agreement was evident in three practices. Fewer than $75 \%$ of both administrators and students agreed that students with special needs should be actively recruited and there was no significant difference in the proportional agreement among administrators and students, $(p>.05)$. However, students mean agreement rating (rating $=3.4$, neutral) was significantly lower that administrators (rating $=4.0$, agree, $\mathrm{t}(83)=2.05$, $\mathrm{p}=.04$ ). In addition, fewer than $75 \%$ of administrators agreed that special admissions procedures should be in place for students with special needs and this proportion did not significantly differ from the proportion of students agreeing, $\mathrm{p}>.05$, or the student level of agreement (ratings, 
$\mathrm{t}(83)=0.21, \mathrm{p}=.84)$. Administrators were concerned about what a specialized admissions procedure would entail. Administrators and students felt that students should meet general entrance requirements for admissions. Some students suggested that special needs students should be part of the recruitment process. One student stated that students prefer to be judged on their grades and achievements rather than their disability. Finally, while $74 \%$ of students agreed (mean rating $=3.9$, agree) with the practice that recruitment/ admissions staff should be knowledgeable about special needs admissions procedures, all administrators agreed that these staff should be knowledgeable (mean rating $=4.5$, strongly agree) and these differences were significant in terms of proportion, $(p<.05)$, and mean ratings $(\mathrm{t}(83)=2.60, \mathrm{p}=.01)$.

Three practices were not strongly followed by administrators (see Table 2). Two of the practices followed by fewer than $55 \%$ of administrators, involved recruitment activities. Administrators were concerned that recruitment activities would be time consuming and that recruitment is not appropriate if services at the postsecondary level are not available. In addition, universities less often reported being involved in recruitment activities than did colleges. Only $58 \%$ of administrators follow special admission procedures for students with special needs. One barrier noted by administrators to this practice was that no guidelines were available about what constitutes a special admission procedure (i.e., lower grades allowed, faster admissions processing, etc.)

\section{Assessment Practices}

Administrators were asked to assess nine possible best practices relating to assessment (see Table 3). Students assessed eight of these practices.

As shown in Table 3, both administrators and students did not strongly support assessment being conducted within three years prior to admissions (mean rating $=3.6$ and 3.3, agree to neutral, respectively; proportional agreement $<59 \%$ ) and reassessments taking place during postsecondary studies (both groups rating $=3.6$, agree; proportional agreement $<57 \%$ ). In addition, only $47 \%$ of administrators supported assessment updates for non-learning disabled students (mean rating $=3.3$, neutral). Comments suggested that administrators believed that reassessment and assessment 
Table 3

Percent Agreeing With and Following Suggested Assessment Practices

$$
\text { Practice }
$$

$\%$ Agree $\%$ Agree $\%$

Administrators Students Follow

1. Assessment updates are conducted for

47

NA 42 non-LD disabled users.

2. Full service is available to students during

$\begin{array}{lll}54 & 82 & 73\end{array}$
the assessment process.

3. Reassessment is conducted during 54 $56 \quad 62$ postsecondary studies.

4. A complete assessment must be conducted 58 44 65 within three years prior to admissions.

5. Individual Education Plans are based on the 100 $85 \quad 87$ assessment and with input from the student.

6. Assessments are held as confidential and 100 93100 only shared after written consent.

\begin{tabular}{lllll}
\hline 7. Assessment results are shared with the student. & 100 & 92 & 96 \\
\hline $\begin{array}{l}\text { 8. Qualified practitioners should conduct and } \\
\text { interpret assessments. }\end{array}$ & 100 & 85 & 87 \\
\hline $\begin{array}{l}\text { 9. Assessment criteria should be standardized } \\
\text { across all postsecondary institutions. }\end{array}$ & 100 & 72 & 82 \\
\hline
\end{tabular}

updates (even within three years prior to admissions) are not always required. Students felt that there are difficulties in obtaining assessments at the secondary level and strict assessment requirements could punish students academically and financially. Students further argued that some disabilities do not change and thus there is little value in reassessment.

Administrators did not strongly support full service during the assessment process ( $54 \%$ agree, mean rating $=3.3$ neutral). Administrators felt that such support is difficult to provide due to staff shortages and funding. In contrast, students strongly supported full service during assessment ( $82 \%$ agree, mean rating $=4.2$, agree $)$ and the 
differences between administrator and student ratings were significant, $(\mathrm{t}(82)=-4.15, \mathrm{p}=.00008)$. Further, while all administrators supported the idea that assessment criterion should be standardized among postsecondary institutions (mean rating $=4.7$, strongly agree), only $72 \%$ of students supported this practice (mean rating $=3.9$, agree) and these differences were significant for proportion, $\mathrm{p}<.05$ and for ratings $t(82)=3.76, p=.0003$. Some students felt that standardized criteria for assessment would limit students' choice and availability of service.

As illustrated in Table 3, administrators noted that four practices were followed by fewer than $75 \%$ of programmes (range between $42 \%$ to $73 \%$ ). These practices involved initial and follow-up assessments and service provision during assessment. Administrators at colleges less often reported following these practices than did administrators at universities. Some administrators stated that one barrier to assessment practices is the lack of evidence that continued assessment is needed. Administrators felt that funding and staffing limitations preclude service during assessment.

\section{Minimum Assessment Criteria}

Learning Disabilities. Administrators were asked to state what items they considered necessary for minimum assessment for Learning Disabilities. Table 4 shows the percent of administrators choosing each item. Overall the majority $(>75 \%)$ felt cognitive abilities, education history, measures of academic achievement, measures of information processing, a diagnostic statement and other issues ruled out should be part of the assessment process. Further, administrators felt the assessments should be conducted by a qualified psychologist or supervised psychological associate.

General Disabilities. Administrators were asked to state what items they considered necessary for minimum diagnostic assessment for disabilities (shown in Table 5). Only two items were considered necessary for minimum assessment (supported by $>75 \%$ ). These items included a diagnostic statement, and an assessment conducted by a qualified health provider. Some administrators mentioned that minimum criteria would 


\section{Table 4}

Percent Administrators Choosing Each item for Minimum Assessment for Learning Disabilities

\section{Item}

Measures of Cognitive Ability (WAIT, WJPB, TOWS)

Educational History

Measures of Academic Achievement

Assessments are conducted by a registered clinical

psychologist or supervised psychological associates

Measures of Information Processing

Diagnostic Statement

Other problems ruled out (i.e., biological, social)

Medical/Developmental History

Intellectual Ability in Average Range (FSI is 90 or better)

Discrepancies of 1.5 or more between aptitude and achievement/information processing
Percent Included

very much depend on the disability and that minimum criteria would change depending on the disability.

Human Resources Practices. Administrators were asked to assess five possible best practices relating to Human Resources. The five practices are found in Table 6. Students were not asked about human resources issues.

While more than $90 \%$ of administrators agree with all of the proposed human resource practices, only $65 \%$ of administrators claimed their programme formally and regularly evaluates staff (see Table 6). Administrators did not comment of the reasons for this lack of evaluation.

Minimum Staffing Requirements for Special Needs Programming. Administrators were asked to indicate the minimum requirements for staffing a special needs programme. Only three positions were deemed required by at least $75 \%$ of administrators. These positions included a learning strategist, a programme coordinator and a programme secretary (see Table 7). 


\section{Table 5}

Percent Administrators Choosing Each item for Minimum Assessment for Disabilities

Item

Percent Included

\begin{tabular}{ll}
\hline Diagnostic Statement & 83 \\
\hline Assessments are conducted by qualified health provider & 83 \\
\hline Audiogram (if applicable) & 50 \\
\hline CNIB registration (if applicable) & 50 \\
\hline Educational History & 42 \\
\hline Medical/Developmental History & 38 \\
\hline Neuropsychological Assessment & 38 \\
\hline Physical Assessment & 21 \\
\hline
\end{tabular}

Table 6

Percent Agreeing With and Following Suggested Human Resource Practices

Practice

$\%$ Agree \% Agree \%

Administrators Students Follow

1. Special needs staff are regularly and formally $\quad 96 \quad$ NA 65 evaluated.

2. Volunteers are trained by special needs.

3. New special needs staff are given job orientation sessions.

4. Staff meet the needs of the special needs programme.

5. Special needs staff have clear written job descriptions. 


\section{Table 7}

Percent Administrators Choosing Each item as Minimum Staff Requirements

Position

Percent Included

\begin{tabular}{ll}
\hline Learning Strategist & 83 \\
\hline Programme Coordinator & 75 \\
\hline Programme Secretary & 75 \\
\hline Technology Interpreter & 67 \\
\hline Peer Support/Volunteers & 58 \\
\hline Academic Counselor & 54 \\
\hline Clinical Counselor & 54 \\
\hline Liaison/Promoter & 25 \\
\hline \hline
\end{tabular}

Table 8

Percent Agreeing With and Following Suggested Program Development Practices

Practice $\quad \%$ Agree \% Agree \%

Administrators Students Follow

\begin{tabular}{llll}
\hline 1. Recommended accommodations are & 100 & 93 & 96
\end{tabular} communicated with faculty.

2. Assistive technologies are integrated into $\quad 95 \quad 69 \quad 43$ general campus settings (i.e., labs)

$\begin{array}{lllll}\text { 3. All accommodations available are compiled } & 83 & 85 & 92\end{array}$ and listed for staff and students

4. A staff member is designated to investigate

$96 \quad 78 \quad 83$
and assist with technologies.

5. Assistive technologies are available $\quad 100 \quad 92 \quad 96$

$\begin{array}{lllll}\text { 6. Accommodations are suggested based } & 100 & 84 & 100\end{array}$ on documentation

7. Students are encouraged to seek services as

$96 \quad 92 \quad 96$
accessed by non-disabled peers (i.e., academic skills).

$\begin{array}{lllll}\text { 8. Suggest accommodations are demonstrated and } & 96 & 86 & 87\end{array}$ monitored by the special needs programme

$\begin{array}{lllll}9 . & \text { The special needs programme arranges individual } & 91 & 97 & 91\end{array}$ accommodations for students. 
Programme Development Practices. Administrators were asked to assess nine possible best practices relating to Programme Development. Students also assessed these practices. The nine practices are found in Table 8.

As illustrated in Table 8, the majority of administrators and students agreed with all of the suggested programme development practices, although students less strongly supported the idea that assistive technologies should be integrated on campus ( $69 \%$ support, rating $=3.8$, agree) than did administrators (95\% support, mean rating $=4.5$, strongly agree) and these differences were significant for both proportion, $(\mathrm{p}<.05)$ and ratings, $(\mathrm{t}(81)=3.12, \mathrm{p}=.002)$. Some students were not sure what these technologies were and thus felt they could not support integration without information. This lack of knowledge of technology by students is supported by the fact only $43 \%$ of the administrators stated that assistive technologies are integrated into the general campus. Administrators noted that their institutions are beginning to investigate possible integration of technology over their campuses. However, one barrier to technology integration noted by administrators is the lack of staff to support technology.

Transition and Outreach Practices. Administrators were asked to assess eight possible best practices relating to Transition and Outreach (see Table 9). Students assessed five of these practices.

As shown in Table 9, more than $75 \%$ of administrators agreed with all but two transition/outreach practices. Students did not show strong support for three practices. Both students and administrators did not strongly support programme communication with parents of students ( $<58 \%$ support, mean ratings $=3.6$ and 3.5 , respectively). Administrators and students commented that their programme is an adult model and communication requires consent. Only $54 \%$ of administrators supported a promotion team representing special needs programmes (mean rating $=3.7$, agree). Administrators stated that promotion is usually integrated with other postsecondary programmes. While administrators supported preparatory courses for postsecondary education $(83 \%$ support, mean rating $=4.1$ ), students were less supportive ( $61 \%$ support, mean rating $=3.7$ ) but these differences were not significant. Some 
Table 9

Percent Agreeing With and Following Suggested Transition and Outreach Practices

Practice $\%$ Agree $\%$ Agree $\%$ Administrators Students Follow

1. Students are given special needs orientation 96 84 71 sessions' prior to or at the start of the academic session.

2. The special needs programme communicates 57 52 71 with and responds to student's parents.

3. Postsecondary preparation courses are offered 83 61 17 to special needs secondary students.

4. Special needs programme promotion is 78 NA $\quad 30$ coordinated with other postsecondary institutions.

5. The special needs programme provides 79 NA $\quad 30$ professional development for secondary teachers and guidance.

6. The special needs programme has a promotion team.

7. Secondary institutions are made aware of the 100 special needs services.

8. Special needs programme brochures describe . 100 the programme (i.e., goals, entrance requirements, services and contact information

students were unaware of what a preparatory course would entail. Interestingly, while $69 \%$ of students supported the practice that secondary schools be made aware of programmes (mean rating $=3.9$ ), all administrators supported this practice (mean rating $=4.7$ ). These differences in opinion between students and administrators were significant for both proportion, $(\mathrm{p}<.05)$ and ratings, $(\mathrm{t}(82)=3.93, \mathrm{p}=.0002)$. Comments suggested that students believed secondary schools are made aware of postsecondary programmes but that this information is not 
passed on to the teachers or students. Students suggested that communication should be directed at students and their teachers rather than through the school (i.e., guidance).

Six practices were not strongly followed by administrators. These practices included offering preparatory courses, programme promotion and offering secondary professional development. Administrators at universities and at large institutions less often reported following these practices than did those at colleges and smaller institutions. Administrators discussed that staffing and funding limitations curtail transition activities. Administrators also stated that standards for transition practice have not been developed and thus the form of these activities (sessions, prep courses, transition mail-out practices) is not clear. In addition, administrators were concerned about promoting services that they may later (due to funding) not be able to provide.

\section{Advising/Counseling Practices.}

Administrators were asked to assess ten possible practices relating to advising and counseling (Table 10). Students assessed nine of these practices.

As illustrated in Table 10, administrators showed strong support for all practices except that only $74 \%$ of administrators supported the integration of academic skills sessions with other non-disabled students (this proportion does not differ significantly from students). Administrators were concerned that academic skills staff might not well understand the needs of students with disabilities. Students did not strongly support several practices. Only $69 \%$ of students support consulting with other departments regarding student need (mean rating $=4.0$ ), while all administrators agreed with this practice (mean rating $=4.9$ ) and these differences were significant for both proportion, $(p<.05)$ and ratings, $(t(83)=5.03, p=.000003)$. In addition the practice of providing or revising a student handbook was not well supported by students $(<57 \%$ support, mean rating $=3.6$ ), but supported by administrators $(>82 \%$ support, mean rating $=4.3$ ) and these differences were significant for both proportion, $(\mathrm{p}<.05)$ and ratings, $(\mathrm{t}(83)=2.99$ [providing handbook], $\mathrm{p}=.004$, $t(83)=2.70, p=.009$ [revising handbook] ). However, administrators at universities and at large institutions less often provided or revised a 
Table 10

Percent Agreeing With and Following Suggested Advising and Counseling Practices

\section{Practice}

$\%$ Agree $\%$ Agree $\%$

Administrators Students Follow

1. Academic skills sessions for students with

74

80

82 special needs are integrated with other postsecondary students.

2. Academic advising for special needs students are integrated with other postsecondary students.

3. Requests by students for learning strategy sessions, academic skill and counseling are dealt with promptly.

4. Meetings with students are arranged to fit the 96

$95 \quad 100$
student's schedule.

5. Special needs programme staff consult with 100

69 92 other campus departments regarding student need (i.e., health).

6. Qualified psychological counselors are 92 $78 \quad 75$ available within the institution.

7. Programme staff are aware of issues that 100 NA 96 warrant professional counseling.

8. Faculty and staff are given in-service training 96 64 67 by special needs

9. The special needs student handbook is 83 52 48 reviewed and updated annually.

10. Students with special needs receive a special 88 56 65 needs student handbook. 
handbook and this is consistent with the fact that many students mention they did not receive a handbook. This lack of familiarity with such a book may have resulted in poor support by students. Administrators confirmed this, as fewer than $66 \%$ of administrators provided and revised a student handbook. In addition, there was poor support by students for in-service training of faculty $(64 \%$ support, mean rating $=3.8)$ but strong support by administrators $(96 \%$ support, mean rating $=4.7)$. The differences in support for in-service between students and administrators was significant for both proportion, $(p<.05)$ and ratings, $(t(83)=3.93, p=.0002)$. One student mentioned that their professors seemed to know how to teach students with special needs. The belief that professors are already trained about these issues might have lead to lower support for further training. Some administrators noted that they do not provide faculty training due to poor attendance at previous sessions (followed by $67 \%$ )

Professional Development Practices. Administrators were asked to assess five possible best practices relating to professional development. Students were not asked about professional development practices. The five practices are found in Table 11.

As illustrated in Table 11, administrators strongly supported all of the proposed professional development practices. However, two practices were not strongly followed by programmes. Practices not consistently followed included the development of internal workshops and training (followed by $64 \%$ ) and the encouragement of staff to hold professional memberships (followed by $71 \%$ ). Funding limitations and time constraints prevented programmes from developing internal workshops. Some administrators also stated that for some jobs (i.e,. learning strategist) there is no professional organization.

Advocacy Practices. Administrators were asked to assess eight possible practices relating to advocacy. Students also assessed each of these practices. The eight practices are found in Table 12.

While all advocacy practices were well supported by administrators, students did not strongly support two practices (see Table 12). First, students less strongly supported the practice of encouraging students to organize $(52 \%$ support, mean rating $=3.7)$ than did administrators $(83 \%$ support, mean rating $=4.1$ ) and these differences were significant for both 


\section{Table 11}

Percent Agreeing With and Following Professional Development Practices

Practice
$\%$ Agree $\%$ Agree $\%$

Administrators Students Follow

1. Internal training/workshops are developed for special needs staff.

2. Special needs staff are encouraged to hold membership in professional organizations.

3. Special needs staff are encouraged to participate 100 in workshops, conferences and meetings.

4. Special needs staff are informed of services, information and resources available through the programme, institution and community.

5. All special needs staff meet regularly to discuss 100 programme needs.

$95 \quad$ NA 64

$88 \quad$ NA $\quad 71$

$96 \quad$ NA 92

NA 96

Table 12

Percent Agreeing With and Following Suggested Advocacy Practices

Practice

$\%$ Agree \% Agree \%

Administrators Students Follow

\begin{tabular}{lllll}
\hline 1. Career planning is available to students & 100 & 85 & 88 \\
\hline 2. Students are apprised of their rights and & 100 & 80 & 92
\end{tabular}
responsibilities

3. Special needs staff review and provide input

100

$80 \quad 71$

to all institutional policy and planning that

affects special needs students.

4. The special needs programme aids students

100

$77 \quad 96$
in advocating their rights to administration, faculty, community and government.

\begin{tabular}{lllll}
\hline 5. Special needs students have peer supports available. & 100 & 80 & 83 \\
\hline 6. Special needs students are encouraged to & 83 & 52 & 57
\end{tabular} organize (i.e., student council)

7. The special needs programme informs 100

$69 \quad 100$
students of legislation and their legal rights.

8. Students are encouraged to advocate for 100

8596


proportion, $(\mathrm{p}<.05)$ and ratings, $(\mathrm{t}(83)=2.12, \mathrm{p}=.04)$. Additionally, the practice of informing students of legal rights was not well supported by students (69\% support, mean rating 3.9), but strongly supported by administrators $(100 \%$ support, mean rating $4.6, \mathrm{t}(83)=3.18, \mathrm{p}=.002)$. Some students felt that these issues are not relevant to them (but see discussion).

Administrators stated that some practices were not consistently followed. According to administrators, only $71 \%$ of programmes review institutional policy. Those that do not review institution policy stated that they are given limited access to institutional policy decisions by their institution. Further, only $57 \%$ of administrators encourage students to organize. Some administrators believe that students do not have the skills needed to organize and that their programmes do not have the time to instill such skills.

Further Practices. Some administrators suggested further practices that could be adopted by programmes. These are listed in Table 13.

\section{DISCUSSION AND CONCLUSIONS}

Overall, there was strong support from both administrators and students for most suggested practice standards. However, in some cases administrators and/or students disagreed with a practice and these practices are highlighted here.

Neither administrators nor students strongly support the idea that students with special needs should be targeted for recruitment. Their comments indicated that minimum university requirements should be met before admissions consideration. Aune (1998) pointed out that admissions offices have a great deal of difficulty determining whether students with learning disabilities are truly qualified for postsecondary education. In addition, Hill (1992) found that only about $30 \%$ of postsecondary institutions surveyed had policies regarding entrance for students with disabilities into their institutions. Lower support for targeted recruitment may reflect both institutional policy (or lack thereof) and unclear definitions of targeted admissions (i.e., specialized admissions does not mean accepting poorer quality students). 


\section{Table 13}

\section{Further Practices Suggested by Administrators}

1. Programmes should have access to technological aids

2. Special needs offices should have advisory committees that liaise with the community.

3. Students should be represented on committees.

4. Special needs policies and procedures should be approved by the board of governors and incorporated into institutional directives.

5. Technologies should be available on a loan basis to students.

6. Courses (i.e., career planning) should be adapted to better fit the needs of special needs students.

7. Transition support should be available to students prior to and after postsecondary training.

8. Admission testing should be waived for special needs students.

9. Feedback on services provided should be gathered from both students and faculty.

10. Students are taught the limits of their disability and how to minimize its impact.

11. Special needs faculty should be added to and integrated with other campus programmes (i.e. career services have a quarter time special needs staff member).

Neither administrators nor students strongly support the idea of reassessment during secondary education and the necessity of assessment three years prior to admission. Both groups indicated that such assessment requirements are not always necessary and that strict assessment requirements can delay service. In addition, administrators did not strongly support the need for assessment updates for students with learning disabilities. Further, administrators but not students supported standardized assessments. One difficulty in assessing students with disabilities is the lack of a functional definition of some disabilities (Leitch, 1998). Currently, as pointed out by Stewart (1995), there is no 
standard criterion for learning disabilities that has been identified and validated. However, experts, like the administrators in this study, argue that assessments should include some specific criteria, including normreferenced tests (Chapman, 1999; Siegel, 1999; University of Alberta, 1993). Siegel (1993) outlines that one difficulty with the use of normreferenced tests for assessment is deciding cut-off for disabilities. Some researchers (see Siegel, 1999) have argued that an arbitrary cut-off on a norm-referenced test could result in less access to service. Students in the current survey echo this concern.

Administrators did not strongly support that departments have promotion teams or that the programme budget to be assessed by an independent assessor. Administrators indicated that time and funding are barriers to these activities. Time and funding barriers were also reflected in practices that administrators agreed with but did not regularly follow. Overall, practices that were supported and not followed were not followed due to time and funding constraints. For example, administrators saw services in the area of professional development (within and external to the institution), recruitment and transition as important, however, current staffing levels allowed for little participation in these activities. Hill (1992) found that average caseload at the postsecondary level was sixty-five students per service provider. In addition, Hill found that only fifty to $66 \%$ of programme directors were full-time. Given the recent increase in number of students attending postsecondary education, caseloads likely have also increased. NEADS (1999a, 1999b) found service and funding limitations throughout Canada and argued that stronger sustainable government funding is needed to build and develop services in Canada.

A few practices were supported by administrators but not by students. Most of these practices revolved around issues of confidentiality and individualism. For example, while administrators agreed that the programme should consult with other departments about student needs, students less strongly felt this should be done. Students may have been in part concerned about the attitude of faculty and staff towards students with disabilities. Vogel et al. (1999) and McBurney (1995) found that most faculty have a positive attitude towards students with disabilities, however, a large proportion of faculty did not have adequate knowledge 
of disabilities. Poor knowledge could lead to attitudinal barriers and misconceptions (i.e., the student with learning disabilities can not handle postsecondary programming, Aune, 1998).

Administrators but not students agreed with a number of promotional and advocacy practices including having students organize, understand legislation, take university prep courses, and receive handbooks. Students also did not support faculty in-service and integrated technology. In part, the lack of support for these issues among students may reflect concerns over time commitments (time to learn legislation, sit on student organizations, sit in prep courses and read handbooks). Students may also have been concerned that some of these practices would affect individualized attention (i.e. read handbooks, rather than receive help). It is also possible that students did not truly understand the value of these services. Greenbaum et al. (1995) and NEADS (1999a) found that some students seem to be unaware of services available to them on and off campus. Aune (1998) argued that one of the greatest barriers in postsecondary education for students is their lack of knowledge about services. This may be in part due to poor co-ordination of service between postsecondary and secondary institutions (Aune, 1998).

Students more strongly supported and agreed with providing full service to students during assessment than did administrators. Students were concerned that lack of service could directly affect the students' ability to cope with postsecondary education. Overall, administrators were concerned with funding and staffing limitations in providing such service. Siegel (1999) argues that the timing of assessments is a concern to both students and programmes. While having an assessment prior to entrance to postsecondary studies is most desirable, assessments are often not complete prior to admissions. Forcing a student to wait until assessments are complete puts the student at both an academic and economic disadvantage (Siegel, 1999).

While our survey involved only Ontario institutions, we believe the results of this study are relevant to other regions of Canada and America. First, the standards of practice suggested here were based on both Canadian and American sources. Second, the barriers and concerns about best practice raised by our survey participants such as institutional 
barriers and funding are not unique to the Ontario. Third, as in other regions of Canada, institutional policy surrounding special needs programming varies among Ontario institutions thus opinion reflects a diverse experience.

Providing standards of practice for postsecondary special needs programming is important in today's climate. The unique contribution of this paper was to highlight strong agreement for most suggested practices among Ontario administrators and students. In addition, we have found that administrators and students are concerned about practices that would hinder confidentiality, reduce individualism, delay service and stretch the programme beyond its ability (due to funding, time limitations and staffing) to provide high quality service. Future research should focus on methods to address these concerns and methods to implement standard practices. Having accepted standards of practice in Ontario and beyond would provide programmes with a benchmark for evaluation and allow for consistent practices and language between programmes.

\section{References}

Albert, J.J., \& Fairweather, J.S. (1990). Effective organization of postsecondary services for students with disabilities. Journal of College Student Development, 3l, 445-453.

Association of Higher Education and Disability (1996). AHEAD Professional Standards. Unpublished manuscript. Columbus, OH: AHEAD.

Aune, B. (1998). Higher education and disability in the United States of America: The context, a comprehensive model and current issues. In A. Hust (Ed.)., Higher education and disabilities: International approaches. Aldershot, UK: Ashgate Publishing Ltd.

Brinkeroff, L.C., Shaw, S., \& McGuire, J.M. (1993). Promoting postsecondary education of students with learning disabilities. Handbook for practitioners. Austin TX: Pro-Ed. Inc.

Chapman University. (1999). Documentation of learning disabilities. Retrieved May, 2000, from Chapman University Web site: http://www.chapman. edu/arc/DocLD.htlm 
Collier, P. (1999). Evaluating teaching: Guidelines and good practice. University of Exiter teaching quality manual. Retrieved May 2, 2000, from University of Exiter Web site: http://www.ex.ac.uk/EAD/Academic/TLA/ TQA/evaluat.htm

Fichten, C.S. (1995). Success in postsecondary education. Rehabilitation Digest, March, 16-20.

Greenbaum, B., Graham, S., \& Scales, W. (1995). Adults with learning disabilities: Education and social experiences during college. Exceptional Children, 61, 460-470.

Greenbaum, B., Graham, S., \& Scales, W. (1996). Adults with learning disabilities: Occupational and social status after college. Journal of Learning Disabilities, 29, 167-173.

Hill, J.L. (1992). Accessibility: Students with disabilities in universities in Canada. The Canadian Journal of Higher Education, XXII, 49-83.

Leitch, D.A. (1998). Canadian universities: The status of persons with disabilities. In.A.Hust (Ed.), Higher education and disabilities: International approaches. Aldershot, UK: Ashgate Publishing Ltd.

McBurney, V. (1995). Attitudes and knowledge of faculty and administrators towards learning: Disabled students and implications for service. Unpublished manuscript: Retrieved May 30, 2000, from Algonquin College Web site: http://www.algonquinc.on.ca/algweb/services/csd/client.htm

NEADS (1999a). National approach to services project. Retained May 7 , $2000 \mathrm{from} h \mathrm{htp} / / \mathrm{www} . n e a d s . c a / P r o j e c t+W o r k / N_{-}$A_S_P_Online/N_A_S_P_ Executive_Summary.html.

NEADS (1999b). Presentaion to the Senate Subcommittee on Postsecondary Education. Retained May 30, 2000 from http://www.neads.ca/ Reports/Senate_Subcommittee.html

Raskin, M.H., Goldberg, R.J., Higgins, E.L., \& Herman, K.L.(1999). Patterns of change and predictors of success in individuals with learning disabilities: Results from a twenty-year longitudinal study. Learning Disabilities Research and Practice, 14(1), 35-49.

Reed, M.J. (2000). Programme self evaluation project: Discussion paper for Special Needs programmes at Trent University, Loyalist College, Canadore College, and Nippising University. Unpublished Manuscript, Trent University, Peterborough, $\mathrm{ON}$.

Rogers, S.J. (2000). The role of nursing theory in standards of practice: A Canadian perspective. Nursing Science Quarterly, 13(3), 260-262. 
Rose, E. (1991). Project TAPE: A model of technical assistance for service providers of college students with learning disabilities. Learning Disabilities, Research and Practice, 6, 25-33.

Royal College of Radiologists Working Party. (1992). Influence of the Royal College of Radiologists guidelines on hospital practice: A multi-centre study. British Medical Journal, 304, 740-743.

Saucier, C.T., \& Gagliano, G.V. (1998). Serving students with disabilities in higher education in the United States of America. In. A. Hust (Ed.), Higher Education and disabilities: International approaches. Aldershot, UK: Ashgate Publishing Ltd.

Siegel, L.S. (1999). Issues in the definition of diagnosis of learning disabilities: A perspective on Guckenberger v. Boston University. Journal of Learning Disabilities, 32, 304-319.

Statistics Canada (1997). Class of 95: Report of the 1997 National Survey of 1995 Graduates. http://www.statcan.ca/Daily/English/990428/d990428c.htm.

Stewart, D., Cornish, P., \& Somers, K. (1995). Empowering students with learning disabilities in the Canadian postsecondary education system. Canadian Journal of Counseling, 29, 70-79.

The Canadian Association of Disability Service Providers in Postsecondary Education (CADSPPE). (1999). Towards developing professional standards of service: A report on support for students with disabilities in postsecondary education in Canada. Retrieved June 2, 2000, from http://www.cadspee. cacuss.ca/english/CADSPEE-Standards/CADSPEE-Standards.html

University of Alberta. (1993). Introduction to the University of Alberta program for students with learning disabilities. Edmonton, AB: Canadian Cataloguing Publication Data.

Vogel, S.A., Leyser, Y., Kwyland, S., \& Brulle, A. (1999). Students with learning disabilities in higher education: Faculty attitude and practice. Learning Disabilities Research and Practice, 14, 173-186.

Virtual Centre of Excellence. (2000). Success indicators. Peterborough, ON: Trent University Special Needs Programme.

Wilchesky, M. (1986). Postsecondary programmes and services for exceptional persons: North American trends. Toronto, ON: Canadian symposium on Special Education Issues: (ERIC Document Reproduction Service No. ED 294 389). 